\title{
KAJIAN KESESUAIAN LAHAN BUDIDAYA TANAMAN OBAT DENGAN APLIKASI SISTEM INFORMASI GEOGRAFIS (SIG) DI KAWASAN SUKU SAMBORI KABUPATEN BIMA
}

\author{
Junaidin ${ }^{1}$, Sugeng Utaya ${ }^{2}$, I Komang Astina ${ }^{3}$, Budi Handoyo ${ }^{4}$ \\ 1 Universitas Negeri Malang \\ 2 Universitas Negeri Malang \\ ${ }^{3}$ Universitas Negeri Malang \\ ${ }^{4}$ Universitas Negeri Malang
}

\begin{abstract}
Abstrak
This research can provide the answer that the potential of the local area is quite potential and needs to be utilized wisely for the welfare of the community. The purpose of this research is to know the potential of medicinal plant cultivation land and to obtain data base on the suitability of medicinal plant cultivation area with application of Geographical Information System (GIS) as a medicinal plant area in Sambore Tribe Area. In this research using survey method with MLA (Multidiciplinaire Landscape Assessment) approach is a method to determine "what resources are most important to society. The research instruments that we present are tools used in research processes such as GPS, benchmarking, thermometer, geological compass, stpowatch, sechi disk, salinometer, and GIS data analysis software and supported by data collection methods that are observation, documentation and experimental methods so this research can be done well.
\end{abstract}

Keywords:

Geographic Information System, Land Fit, Data Base.

\section{PENDAHULUAN}

Satu di antara kendala dalam pengembangan wilayah lahan Kawasan Sambori Kabupaten Bima di Nusa Tenggara Barat adalah masih terbatasnya data rinci dan informasi mengenai ketepatan kelayakan potensi sumberdaya lahan Kawasan Suku Sambori di daerah tersebut, data rinci dan informasi mengenai hasil survei kelayakan potensi sumberdaya lahan sebagai budidaya tanaman obat yang dibuat dalam bentuk peta prospektif.

Penelitian menyangkut pengelolaan dan pengembangan wilayah lahan Kawasan Sambori Kabupaten Bima yang dapat dikembangkan adalah pemetaan kesesuaian lahah sebagai budidaya tanaman obat dengan aplikasi Sistem Informasi Geografis (SIG). SIG dapat digunakan untuk mengidentifikasi potensi sumberdaya wilayah lahan sebagai budidaya tanaman obat dalam skala global yang dapat dilakukan secara efektif dan akurat. Dari berbagai sudut pandang yang dikaji, maka penulis memiliki ketertarikan untuk mngambil judul "Pemetaan Kesesuaian Lahan Budidaya Tanaman obat dengan Aplikasi Sistem Informasi Geografis (SIG) di Kawasan Suku Sambori Kabupaten Bima”.

\section{METODE PENELITIAN}

Metode penelitian yang digunakan pada penelitian ini adalah metode survei menggunakan pendekatan metode MLA (Multidiciplinaire Landscape Assesment) yaitu suatu metode untuk menentukan "sumber daya apa yang paling penting bagi masyarakat Kawasan Suku Sambori dalam "Pemetaan Kesesuaian Lahan budidaya tanaman Obat dengan Aplikasi Sistem Informasi Geografis (SIG)". Pendekatan ini bersumber pada aspek sosial (antropologi, etnobotani, sosial-ekonomi) sebagaimana juga aspek pengetahuan alam (ekologi, botani, pedologi, geografi). Sheil dkk., 2004: http://www.cifor.cgiar.org/mla/). Penggunaan survei menggunakan pendekatan metode MLA biasanya terdiri dari: 'tim desa' (yang melakukan dan menggunakan berbagai sarana survei di desa) dan 'tim lapangan' (yang melakukan studi ekologi dengan membuat plot-plot di setiap lanskap). Penelitian ini memfokuskan pada hasil studi dari tim desa, lebih spesifik lagi dari hasil pemetaan bersama masyarakat, wawancara, kuesioner dan hasil kegiatan PDM (Pebble Distribution Method). 
Rancangan yang digunakan dalam penelitian ini adalah penelitian deskriptif dengan pendekatan survei. Menurut Riyanto, (2001:23) penelitian deskriptif adalah "penelitian yang diarahkan untuk memberikan gejala-gejala, fakta-fakta atau kejadian-kejadian secara sistematis dan akurat, mengenai sifat-sifat populasi atau daerah tertentu". Berdasarkan pendapat ahli diatas maka dalam penelitian ini menggunakan pendekatan survei untuk mengetahui bagaimana Kesesuaian Lahan Budidaya Tanaman obat dengan Aplikasi Sistem Informasi Geografis (SIG) yang disajikan dalam bentuk peta dan data di Kawasan Suku Sambori Kabupaten Bima.

Lokasi yang dipilih oleh peneliti yaitu di daerah Kawasan Suku Sambori Kabupaten Bima yang meliputi tiga dusun, yaitu Dusun Lambitu, Dusun Lengge 1 dan Dusun Lengge 2, yang terdiri dari 4 RW dan 10 RT. Waktu penelitian dilaksanakan pada bulan April sampai pada bulan Mei 2017.

Dalam penelitian Pemetaan Kesesuaian Lahan budidaya tanaman Obat dengan Aplikasi Sistem Informasi Geografis ini bahan yang digunakan antara lain: laporan survey dan penelitian sebelumnya yang menunjang, peta kawasan, informasi lain yang digali langsung dari pengelola teknis, pemerintah daerah, masyarakat dan pengunjung. Peralatan yang digunakan antara lain: kaset rekaman untuk kepentingan dokumentasi, komputer/laptop, alat tulis lainnya selain itu Instumen Penelitian menurut Ibnu Hadjar (2006:160), adalah alat ukur mendapatkan informasi kualitatif tentang variasi alat yang digunakan untuk mengetahui Kesesuaian Lahan Budidaya Tanaman obat dengan Aplikasi Sistem Informasi Geografis (SIG) yang disajikan dalam bentuk peta ( gambar 2 dan 3) dan data (table 1) di Kawasan Suku Sambori Kabupaten Bima., dapat dilihat sebagai berikut.

Tabel 1. Aplikasi Sistem Informasi Geografis (SIG) di Kawasan Suku Sambori Kabupaten Bima

\begin{tabular}{|c|c|c|c|}
\hline No & Nama Alat & Jumlah & Kegunaan \\
\hline 1 & Global Positioning System (GPS) & 1 buah & $\begin{array}{l}\text { Penentu posisi stasiun } \\
\text { pengamatan }\end{array}$ \\
\hline 2 & Rambu ukur/tiang skala & 1 buah & $\begin{array}{ll}\text { Pengukur } & \text { Tingkat } \\
\text { Kemiringan Lereng } & \end{array}$ \\
\hline 3 & Termometer & 1 buah & Mengukur Suhu \\
\hline 4 & Tali pengukur & 1 buah & Pengukur Luas Lahan \\
\hline 5 & Kompas Geologi & 1 buah & Penentu arah \\
\hline 6 & Stopwatch & 1 buah & Penentu/menghitung waktu \\
\hline 7 & Secchi disk & 1 buah & Mengukur Kecerahan \\
\hline 8 & Kamera Foto Digital & 1 buah & Dokumentasi proses \\
\hline 9 & Alat tulis menulis & 1 set & $\begin{array}{l}\text { Pencatatan } \\
\text { pengukuran }\end{array}$ \\
\hline 10 & Cool Box & 2 buah & WadahPenyimpanan Sampel \\
\hline 11 & Kertas Label & - & Pelabelan sample \\
\hline 12 & Software pengolah data (MS Excel) & 1 buah & Mengolah data \\
\hline
\end{tabular}


Sumber: Dokumentasi Kantor Desa Sambori, dikutip tanggal, 14 April 2017.

Dalam observasi ini peneliti melakukan suatu pengamatan dan pencatatan secara sistematis terhadap gejala/fenomena yang diselidiki untuk menjelaskan tentang Pemetaan Kesesuaian Lahan Budidaya Tanaman obat dengan Aplikasi Sistem Informasi Geografis (SIG) di Kawasan Suku Sambori Kabupaten Bima Tahun 2016.

Sehubungan dengan penelitian ini, metode dokumentasi digunakan untuk mengetahui tentang data satelit dan peta serta hasil pencatatan berdasarkan observasi lapangan yang disajikan wilayah yang akan dijadikan sebagai tempat budidaya tanaman obat dengn parameter sifat kimia dan aplikasi Sistem Informasi Geografis (SIG).

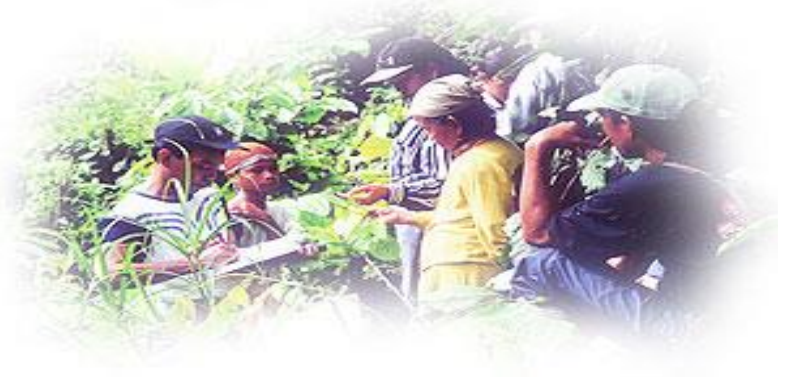

Gambar 1 Metode Dokumentasi

Menurut Sugiyono (2000:14), "Data kualitatif adalah data yang berbentuk kalimat, kata atau gambar. Sedangkan data kuantitatif adalah data yang berbentuk angka, atau data kualitatif yang diangkakan (skoring)". Sehubungan dengan hal tersebut, maka dalam penelitian ini jenis data yang digunakan adalah jenis data kualitatif.

Menurut Surakhmad (2008:134) sumber data menurut sifatnya digolongkan menjadi dua, yaitu sumber data primer dan sumber data sekunder. Data yang dipergunakan dalam penelitian ini adalah sumber data primer yang diperoleh dari hasil data satelit, observasi serta dokumentasi lapangan. Dan sumber sekunder yang diperoleh dari dokumen-dokumen yang lainnya.

\section{ANALISIS DAN PEMBAHASAN}

Langkah awal yang dilakukan dalam pemetaan bersama masyarakat adalah menggambar peta lanskap dengan nama-nama lokal dari setiap satuan lanskap di kawasan Suku Sambori tersebut seperti sungai-sungai dan tempat-tempat lain di mana sumber daya alam utama ditemukan. Pemetaan ini dibuat bertujuan untuk mengetahui bagaimana Kesesuaian Lahan Budidaya Tanaman obat dengan Aplikasi Sistem Informasi Geografis (SIG) di Kawasan Suku Sambori Kabupaten Bima.

Survei desa dilakukan dengan metode kuesioner kepada hampir seluruh rumah tangga yang ada di Kawasan Suku Sambori. Informasi yang dikumpulkan dari setiap kepala keluarga meliputi tingkat pendidikan, sumber pendapatan utama dan mata pencaharian. Kuesioner tersebut juga mengumpulkan informasi dasar mengenai pandangan masyarakat lokal tentang ancaman yang berkaitan dengan keanekaragaman hayati, perspektif terhadap pengelolaan dan konservasi sumber daya alam, dan penguasaan atas lahan. Selanjutnya dilaksanakan kegiatan skoring, dimana para informan diminta untuk mendistribusikan 100 kacang atau kerikil pada kartu-kartu berilustrasi menurut kepentingan mereka. Kegiatan skoring ini dilakukan untuk menilai tentang : 1. tipe-tipe lahan, seperti yang ditetapkan oleh masyarakat; 2. hutan pada masa dulu, masa kini dan masa yang akan datang; 3. sumber-sumber yang berbeda dari tumbuhan dan hewan (liar, ditanam/dipelihara, dibeli); 4. jenis tumbuhan dan binatang dari masing-masing kategori kegunaan, sebagaimana ditetapkan oleh masyarakat untuk mengetahui bagaimana Kesesuaian Lahan Budidaya Tanaman obat dengan Aplikasi Sistem Informasi Geografis (SIG) di Kawasan Suku Sambori Kabupaten Bima. 


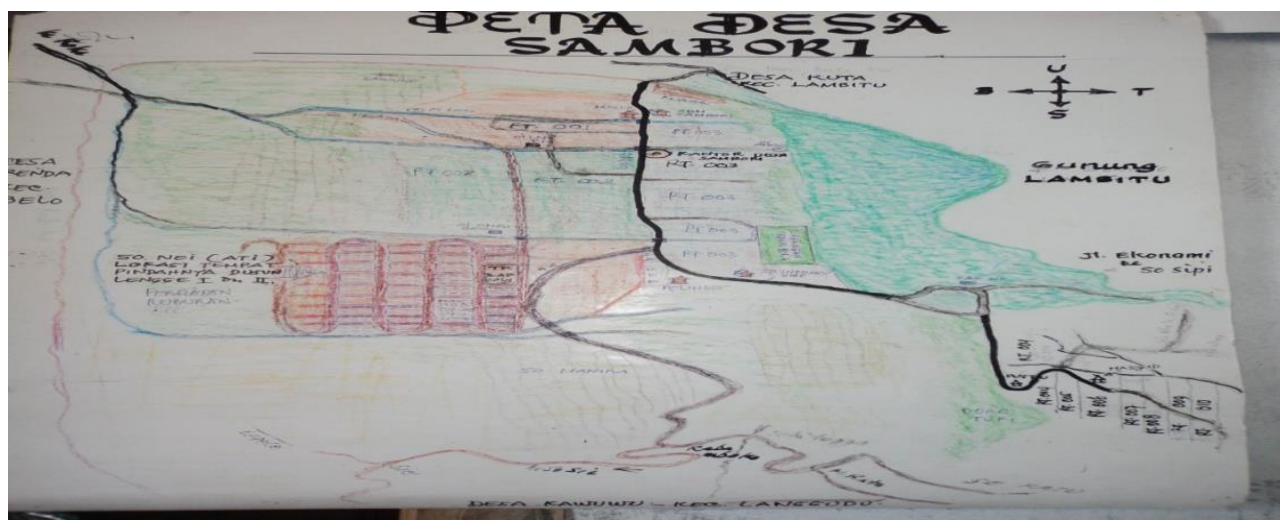

Sumber: Dokumentasi Kantor Desa Sambori, dikutip tanggal, 14 April 2017

Gambar 2 Peta Desa

\section{Pembagian Lahan Berdasarkan Pola Spasial Kawasan Suku Sambori}

\section{Kabupaten Bima}

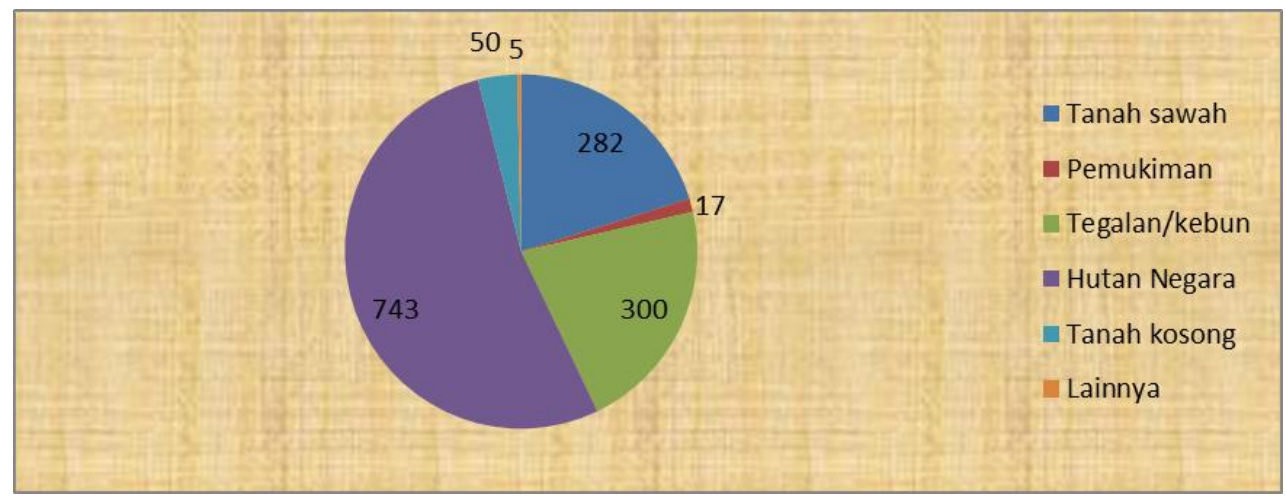

Gambar 3

Pembagian satuan lingkungan oleh masyarakat Suku Sambori pada awalnya dibagi atas hasil kesepakatan para sesepuh tokoh adat dan tokoh agama yang sudah lama menetap di kawasan Suku Sambori Desa Sambori. Pembagian satuan lingkungan ini bertujuan untuk melakukan analisis pola spasial penggunaan lahan yang sesuai dengan kemampuan lahan dan mengikuti kaidah-kaidah tata ruang di Kawasan Suku Sambori. Adapun pembagian satuan lingkungan oleh masyarakat Kawasan Suku Sambori dapat dilihat pada Tabel 2 sebagai berikut:

Tabel 2. Pembagian Satuan Lingkungan Oleh Masyarakat Kawasan Suku Sambori

\section{No Satuan Lingkungan Deskripsi Manfaat}

\begin{tabular}{lll}
\hline 1 & Dusun Lengge 1 & $\begin{array}{l}\text { Dusun Lengge 1 ialah kawasan suku yang dijadikan sebagai pusat tempat } \\
\text { tinggal yang berada di kawasan bagian bawah bukit dan lembah }\end{array}$ \\
2 & (Suku Sambori) & $\begin{array}{l}\text { Dusun Lengge 2 ialah kawasan suku yang dijadikan sebagai pusat tempat } \\
\text { tinggal yang berada di kawasan lereng gunung Lambitu yang merupakan } \\
\text { pemukiman baru. }\end{array}$ \\
\hline
\end{tabular}


3 Woha'arak

(hutan primer)

$4 \quad$ So (kawasan luas)

5 Bangga (sawah)

6 Oma (tegalan)

$7 \quad$ Rasa (pemukiman)
Woha'arak atau hutan primer merupakan kawasan hutan yang sengaja dibiarkan oleh masyarakat Sambori karena dipercaya menjadi sumber mata air.

So merupakan kawasan paling luas di Desa Sambori yang mencakup lebih dari 50 \% dari luas wilayah Sambori. So merupakan kumpulan dari beberapa kawasan yang ada di Sambori yang dimanfaatan untuk bertani dan berladang serta aktifitas yang lain.

Bangga (sawah) merupakan lahan pertanian tadah hujan yang dipakai untuk menanan tanaman komoditi pangan maupun obat.

Oma (tegalan) merupakan kawasan pegunungan yang dimanfaatkan sebagai ladang

Rasa (pemukiman) merupakan kawasan yang berisi rumah-rumah penduduk

Sumber: Dokumentasi Kantor Desa Sambori, dikutip tanggal, 14 April 2017.

Mata pencaharian masyarakat Kawasan Suku Sambori didominasi oleh petani dengan memanfaatkan lahan yaitu petani ladang, kebun serta tegalan. Sebagian besar masyarakat Suku Sambori memiliki lahan untuk kegiatan pertanian seperti sawah dan ladang tegalan yang sangat luas dengan status kepemilikan yaitu sawah hak milik serta tegalan sebagian besar belum memiliki sertifikat hak milik namun masyarakat Sambori membayar pajak hak guna pakai. Masyarakat yang tidak memiliki lahan pertanian biasanya bekerja membantu petani yang memiliki lahan sendiri demi mendapatkan upah yang tidak seberapa dan tidak menentu tergantung keikhlasan pemilik lahan.

Sebagian lahan yang ada di Sambori digunakan oleh masyarakat untuk membudidayakan tanaman kunyit dan tempuyang. Kedua tanaman tersebut merupakan tanaman komoditi khas Desa Sambori selain bawang putih dan tanaman obat. Oleh karena itu masyarakat Sambori merupakan desa dengan ciri khas masyarakatnya yang identik dengan membudidayakan serta berdagang tanaman obat dan bawang putih. Tamanan obat yang sudah dipanen seperti bawang putih, tempuyang, kunyit, lengkuas di jajakan secara oleh masyarakat Sambori ke seluruh wilayah Bima maupun Dompu dengan sistem pembayaram menggunakan uang maupun dengan menukar dengan barang atau kebutuhsn yang lain yang dikenal dengan istilah kancao (barter). Sebagian tanaman yang dipanen disimpan untuk dipergunakan dalam memenuhi kebutuhan hidup dan obat-obatan tradisional.Dibawah ini dapat terlihat gambar 4 hasil pertanian, petani ading, kebun serta tegalan masyarakat Suku Sambori Kabupaten Bima:

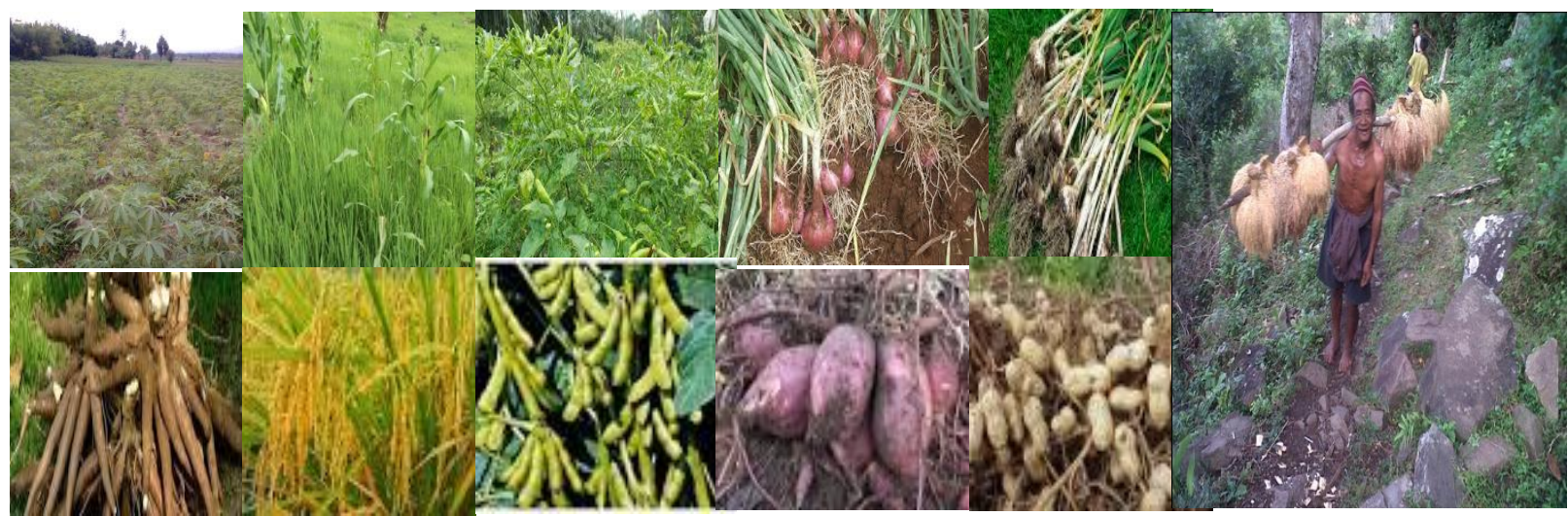

Sumber: Dokumentasi tanggal 9 s.d 11 April 2017

Gambar 4. Hasil Pertanian 
Tanaman pangan tersebut dimanfaatkan untuk memenuhi kebutuhan pokok sehari-hari. Padi atau nama latinnya adalah Oryza sativa merupakan tanaman pangan yang pokok. Selain padi, tanaman pangan yang sering dimanfaatkan untuk memenuhi kebutuhan pokok masyarakat Sambori sehari-hari adalah jagung.Hal ini dikarenakan pembudidayaan tanaman tersebut tidak terlalu sulit dan tidak membutuhkan lahan khusus. Tanaman jagung ini dapat dibudidayakan di sela-sela tanaman lain.Tanaman yang menjadi komoditi adalah tanaman toga yang dibudidayakan di kawasan Sambori antara lain jahe (Zingiber officinale), kunyit (Curcumae Domesticae), lengkuas (Alpinia galanga), mengkudu (Morinda citrifolia L), temulawak (Curcuma xanthorrhiza), kumis kucing (Orthosiphon stamineus), kencur (Kaempferia galanga), bangle (Zingiber purpureum), lempuyang (Zingiber spp) dan lain-lain.Umumnya tanaman tumbuh di sekitar sumber mata air atau mada oi. Selain itu masyarakat Sambori mengembangbiakan atau mebudidayakan tanaman toga tersebut di pekarangan rumah yang kondisi lingkungan tumbuhnya hampir sama dengan lingkungan tumbuhnya yang ada di hutan sekitar pemukiman Sambori.

Peternakan kawasan Sambori biasa dijumpai jenis ternak seperti kuda, kerbau, sapi dan unggas.Kebiasaan beternak secara turun temurun dilakukan oleh masyarakat Sambori, namun jumah hewan ternak yang dipelihara semakin sedikit karena berkurangnya pakan ternak dan banyak yang dijual. Dibawah ini dapat terlihat gambar 6 Flora dan Fauna Kawasan Suku Sambori:

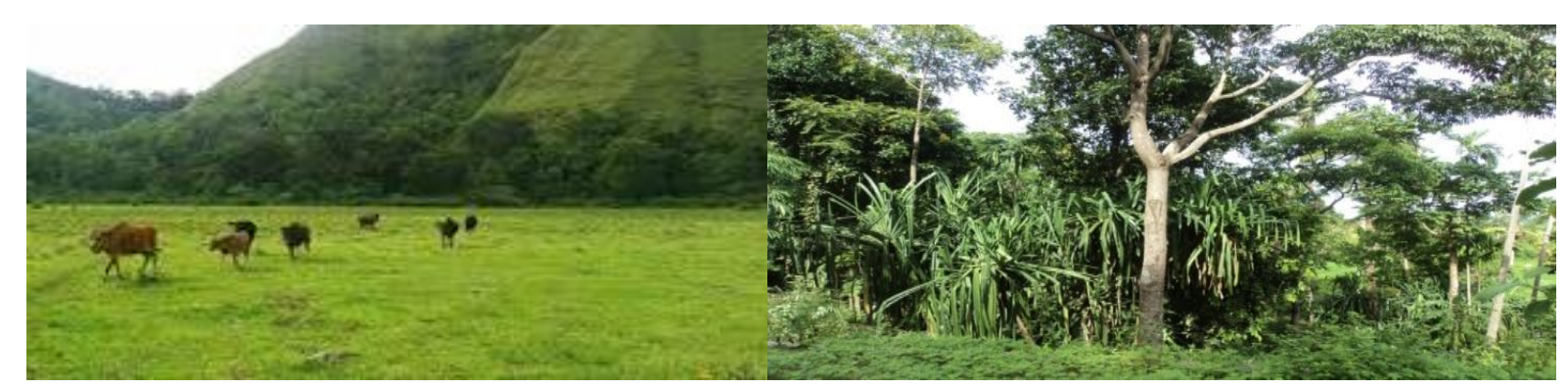

Sumber: Dokumentasi tanggal 9 s.d 11 April 2017

Gambar 6. Flora dan Fauna Kawasan Suku Sambori

Masyarakat yang bermukim di Dusun Lengge 1 dan Lengge 2 memiliki tradisi atau kepercayaan yang lebih kental dibandingkan dengan masyarakat Sambori yang bermukim di dudun Lambitu atau Sambori Bou (baru). Hampir semua masyarakat Sambori tinggal dirumah panggung dan setiap rumah tersebut ditinggali oleh satu kepala keluarga yang disebut keluarga batih (inti).

Budaya yang paling dapat dilihat dimasyarakat Sambori ialah Mama ro,o nahi(menginang) yang merupakan kebiasaan sehari-hari masyarakat Sambori. Mama ro,o nahi (menginang) ini juga menjadi suguhan kepada tamu yang datang kerumah warga Sambori yang merupakan suatu bentuk penghormatan serta dapat diartikan sebagai bentuk ungkapan penerimaan terhadap tamu tersebut dalam suasana kekeluargaan yang erat. Masyarakat Sambori mempercayai bahwa menginang merupakan tradisi yang banyak memberikan manfaat seperti menyembuhkan penyakit pada gigi, menguatkan gigi, serta menghangatkan tubuh.

Masyarakat Sambori lama juga memiliki kepercayaan bahwa memiliki istri lebih dari satu dan memiliki anak banyak dapat mendatangkan rezeki banyak, karena mereka juga mengajak anak serta istrinya untuk bertani di sawah, ladang maupun tegalan dan kebun, namun kepercayaan tersebut lambat laun memudar teriring dengan meningkatnya kesadaran masyarakat Sambori untuk mengenyam pendidikan setinggi-tingginya. 


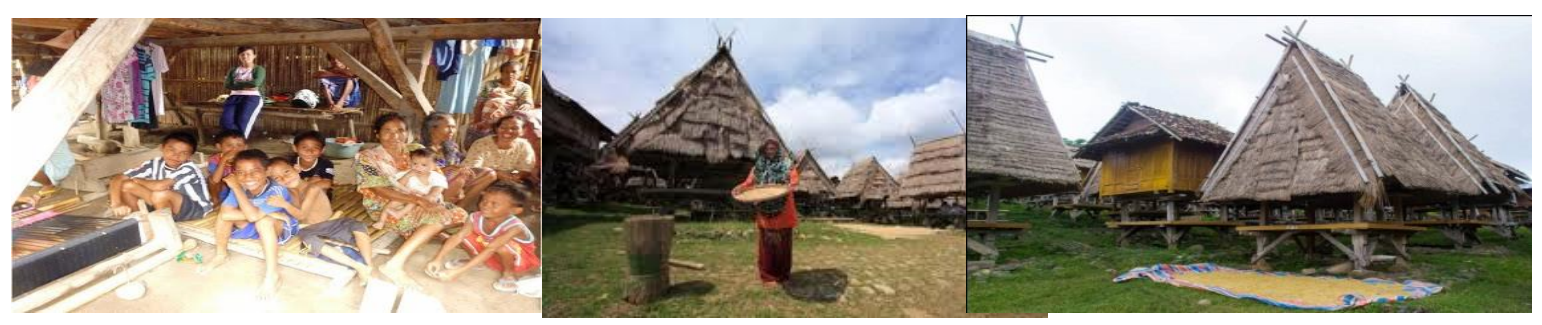

Sumber: Dokumentasi tanggal 9 s.d 11 April 2017

\section{Gambar 7. Budaya Masyarakat Sambori}

Pada saat ini kondisi ataupun tinglat partisipasi pendidikan masyarakat Sambori sangat baik dan meningkat tajam. Masyarakat Sambori saat ini menyekolahkan anak-anaknya sampai perguruan tinggi ke berbagai perguruan tinggi terbaik di Indonesia. Oleh karena itu banyak anak-anak Sambori yang menajdi orang-orang yang berhasil di rantauan.

Masyarakat Sambori memiliki kondisi kesehatan yang baik serta kondisi fisik yang baik karena kebiasaan mereka yang bertani serta berladang pada kawasan berbukit-bukit sehingga masyarakat Sambori memiliki fisik yang bugar sebagai bentuk adaptasi terhadap lingkungan mata pencaharian untuk memenuhi kebutuhan hidupnya. Pengobatan bagi warga yang sakit, masyarakat Sambori mengobatinya dengan cara membawa atau memanggi Samdo (dukun) untuk melakukan ritual ufiyakni membaca do'a sambil meniup bagian tubuh yang sakit dan mengusap ngusap kepala dan bagian tubuh yang sakit.Untuk mengobati penyakit yang berbahaya seperti cacar atau penyakit menahun lainnya, masyarakat akan mengadakan suatu pengobatan khusus dengan nyanyian. Nyanyian ini sekaligus menjadi mantra untuk memohon kesembuhan kepada sang khalik. Di desa sambori terdapat beberapa orang memiliki pekerjaan dalam bidang kesehatan. Untuk anggota masyarakat yang biasanya melakukan praktek kesehatan di Desa Sambori, tercatat 3 orang Dukun bayi dan 3 orang Dukun sunat, 2 orang Bidan Desa. Masyarakat Sambori hanya memiliki 4 buah sumur.

Masyarakat Sambori memiliki cara atau tradisi dalam melakukan pengobatan terhadap orang yang terkena sakit. Pengobatan yang dilakukan yaitu dengan dua cara yaitu pertama dengan cara ufi (membacakan mantra tertentu kemudian meniupkan ke orang yang sakit atau membacakan mantra tertentu pada segelas air lalu diberikan ke orang yang sakit untuk diminum. Cara yang kedua ialah dengan memberikan ramuan atau obat-obatan yang dibuat dengan bahan tumbuhan yang hidup di pekarangan atau di hutan.

Bahan-bahan seperti daun bidara (ro'o rangga) (Ziziphus mauritiana) bagian pucuk, tanaman kunyit (Curcuma longa), beras (fare monca) (Oriza satifa), ketan hitam, daun delima (Punica granatum). Untuk pembuatannya, daun bidara (Ziziphus mauritiana) direbus terlebih dahulu sambil diaduk-aduk sampai air kelihatan keruh, setelah air mendidih diangkat dan didiamkan selama 10 sampai 20 menit, kemudian diminum. Selanjutnya tanaman kunyit (Curcuma longa), beras (vare monca), dicampur dan ditumbuk sampai halus kemudian dioleskan ke seluruh tubuh adar bintik cacar cepat muncul pada permukaan kulit. Setelah bintik cacar sudah muncul sebaiknya ketan hitam dan daun delima yang telah dihaluskan tadi langsung dioleskan keseluruh tubuh sehingga bintik cacar tadi akan lebih cepat kering. Selain beberapa bahan diatas ada pula bahan-bahan lain yang dimanfaatkan sebagai obat cacar, seperti akar ruku-ruku hutan (Alpinia galanga L.) atau masyarakat Sambori biasa menyebutnya dengan "pataha doro", kenanga (Cananga odorata), dan bunganya cempaka (Michelia champaca). Hanya saja cara pemanfaatannya yang beda yaitu semua bahan ditumbuk dan dikunyah.

\section{Obat Panas.}

Bahan-bahan yang digunakan sebagai obat panas oleh masyarakat Sambori yaitu daun melati dan daun jinten (bumbujo).Melati dn bumbu jo ini biasanya ditanam di pekarangan rumah maupun di kebun yang ada di sekitar kawasan pemukiman yang sering disebut Nggaro (kebun). Cara pembuatan obat ini ialah dengan caradaun melati (Jasminum sambac) dan daun jintan (Cuminum cyminum L.) atau masyarakat Sambori menyebutnya dengan "bumbujo". Daun melati ditumbuk hingga halus dan di tempel pada dahi anak-anak.Sedangkan untuk daun jinten (bumbujo) diremas dan ditambah dengan sedikit minyak telon atau minyak kayu putih kemudian dioleskan keseluruh tubuh dan diselimuti sampai keluar keringat.

\section{Obat Kencing Batu.}

Obat kencing batu biasanya masyarakat Sambori memanfaatkan tumbuhan kumis kucing untuk bahan pengobatan. Cara pembuatanya: tumbuhan kumis kucing direbus terlebih dahulu dengan dua gelas air dan sedikit tambahan minyak kelapa sampai mendidih, diangkat dan langsung diminum. 
Tabel 3. Daftar JenisTanaman Obat-Obatan Yang Ditanam Dipekarangan Rumah

\begin{tabular}{cll}
\hline No & \multicolumn{1}{c}{ Nama/jenis Tanaman } & \multicolumn{1}{c}{ Manfaat/Kegunaan } \\
\hline 1 & Mengkudu & obat keluarga \\
2 & Temu lawak & pelangsing \\
3 & Temu mangga & cacing kremi \\
4 & Temu giring & pelangsing \\
5 & Lempuyang & panas \\
6 & Kunyit & mag \\
7 & Temu hitam & penambah nafsu makan \\
8 & Kumis kucing & kencing batu \\
9 & Jintan putih & Penurun panas \\
10 & Kunyit putih & kangker \\
11 & Sirih & Keputihan \\
12 & Lengkuas & kecantikan kulit \\
\hline
\end{tabular}

Sumber: hasil wawancara, tanggal 9 s.d 11 September 2016

Namun eksistensi pengetahuan lokal masyarakat Sambori mengenai pemanfaatan tumbuhan lokal untuk pengobatan ini di khawatirkan akan lambat laun tergerus karena adanya pengobatan secara modern serta budaya dari luar. Perubahan sudut pandang masyarakat terhadap pengobatan tradisional disebabkan oleh fakator budaya luar, tingkat pendidikan yang semakin meningkat.

\section{Tumbuhan Untuk Kerajinan}

Masyarakat Sambori pada umumnya memanfaatkan jenis tumbuhan yang berpotensi sebagai bahan kerajinan/anyaman yaitu seperti yang tersaji pada Tabel 4 dibawah ini.

Tabel 4. Daftar jenis tumbuhan untuk bahan kerajinan.

\begin{tabular}{|c|c|c|c|}
\hline No & $\begin{array}{c}\text { Nama / Jenis } \\
\text { Tumbuhan }\end{array}$ & Jenis kerajinan & $\begin{array}{c}\text { Tempat } \\
\text { pengambilan }\end{array}$ \\
\hline 1 & Daun Pandan & Lupe & Hutan \\
\hline 2 & Daun Lontar & Tikar & Hutan \\
\hline 3 & Bambu legi & Saduku/tempat menyimpan nasi & Hutan \\
\hline
\end{tabular}

Sumber: Hasil wawancara, tanggal 9 s.d 11 September 2016

Di desa Sambori, kerajinan tangan sudah ada sejak jaman nenek moyang mereka.Baisanya, kerajinan tangan tersebut terbuat dari daun lontar (Borassus flabellifer), daun Pandan (Pandanus tertorius)seperti pada gambar 3 dan bamboo (Gigantochloa atter). Kerajinan tangan tersebut berupa tikar, saduku/kula (tempat nasi), tas, dompet dan kerajinan lainya. Kerajinan-karajinan tersebut biasanya dijual dan dimanfaatkan untuk keperluan sehari-hari, seperti tikar yang digunakan untuk alas tempat duduk apabila ada tamu yang datang untuk berkunjung, Saduku yang digunakan untuk minyimpan nasi serta berbagai aksesoris lainya.Biasanya, bahan-bahan untuk pembuatan kerajinan tersebut dapat diperoleh dari hutan ataupun dibudidayakan langsung di pekarangan rumah.

Kondisi topografi kawasan Sambori yang terlat di perbukitan dengan ketinggian 1120 mdpl memiliki kondisi lingkungan yang sangat baik untuk ditumbuhi oleh tanaman obat keluarga atau yang dikenal sebagai tanaman toga. Untuk mengawali musim tanam, masyarakat Sambori biasanya melakukan 
ritual adat yang disebut sebagai upacara Pamali Manggodo sebagai harapan agar tanaman yang ditanama dapat dipanen hasilnya secara berlimpah dan dijauhkan dari hama dan penyakit. etnobotani merupakan disiplin ilmu mengenai hubungan interaksi antara tumbuhan dan manusia. Hubungan antara tumbuhan dan kebudayaan manusia tidak hanya terbatas pada kebutuhan manusia untuk pangan, pakaian dan bangunan, tetapi juga termasuk ke dalam penggunaan tumbuhan untuk keperluan agama, hiasan dan obat.Di daerah Sambori, bahan-bahan untuk pembuatan rumah tersebut dapat diperoleh langsung dari hutan.Selain dari hutan, pohon-pohon tersebut dilestarikan langsung oleh masyarakat Sambori sehingga dapat dimanfaatkan lagi untuk beberapa tahun kedepan. Dalam proses pengambilanya, pohon-pohon yang akan dijadikan sebagai bahan pembuatan rumah dipilih terlebih dahulu pohon-pohon yang memiliki kualitas yang baik untuk dijadikan bahan bangunan. Seteleh pohon sudah ditentukan, selanjutnya langsung ditebang menggunakan kapak.Setelah itu pohon tersebut langsung dipotong sesuai dengan ukuran yang dibutuhkan.

Tradisi mama atau menginang masyarakat Sambori sudah menjadi turun temurun.Hal ini mereka sudah benar-benar memahami tentang manfaat nginang untuk kesehatan.Kebiasaan masyarakat Sambori yang memakan daun sirih selain bermanfaat sebagai pengusir kuman penyakit atau penguat gigi, juga dikarenakan suhu dan udara di desa Sambori yang memang sangat dingin sehingga untuk menghilangkan kedinginan mereka memakan daun sirih yang telah dicampur dengan tembakau sehingga badan mereka menjadi hangat.

Nahi (daun sirih),termasuk jenis tumbuhan merambat dan bersandar pada batang pohon lain. Bentuk daunnya pipih menyerupai jantung dan tangkainya agak panjang.Permukaan daun berwarna hijau dan licin, sedangkan batang pohonnya berwarna hijau gelap (hijau agak kecoklatan) dan permukaan kulitnya kasar serta berkerut-kerut.Daun sirih disamping untuk keperluan ramuan obat-obatan juga masih sering digunakan oleh ibu-ibu generasi tua untuk kelengkapan 'nginang' (Jawa).Avu bahan untuk menginang di dapatkan masyarakat Sambori dengan cara karang dibakar menggunakan kotoran kerbau.

\section{KESIMPULAN}

Berdasarkan hasil dan pembahasan Kesesuaian Lahan Budidaya Tanaman obat dengan Aplikasi Sistem Informasi Geografis (SIG) yang disajikan dalam bentuk peta dan data di Kawasan Suku Sambori Kabupaten Bima dengan survei menggunakan pendekatan metode MLA berdasarkan hasil survey Masyarakat pedesaan khususnya masyarakat suku Sambori yang hidup dikawasan hutan menggantungkan hidupnya kepada lingkungan dan alam sekitarnya. Interkasi antara masyarakat suku Sambori dengan dengan lingkungannya memanfaatkan bentang alam, bentang daratan, lanscope melahirkan budaya serta pengetahuan yang secara tidak disengaja menjadi kesepakatan dalam bentuk perilaku masyarakat dalam memenuhi kebutuhan hidupnya sehari-hari. Pembagian satuan lingkungan oleh masyakat Suku Sambori pada awalnya dibagi atas hasil kesepakatan para sesepuh desa yang sudah lama menetap di desa Sambori.

Hasil penelitian ini yang menarik mengenai keanekaragaman dari setiap kegunaan yang berhubungan dengan pembagian lahan adalah ketika masyarakat ditanya mengenai unit lahan tertentu. Mereka memberikan khisaran yang luas mengenai kegunaan praktis yang dikaitkan dengan semua sumber-sumber alami (untuk berburu, mengumpulkan buah-buah, dan lain-lain.). Tetapi mereka juga memberikan beberapa jawaban yang lebih merupakan kepentingan kultural. Hutan larangan atau pegunungan Sambori merupakan contoh yang baik mengenai nilai-nilai kegunaan praktis dan kultural tersebut. Begitu juga untuk unit lanskap seperti sungai-sungai yang memainkan peranan penting sebagai sumber bahan makanan dan hasil lainnya. Selain itu sungai juga berperan sebagai batas wilayah dan jalur utama transportasi.

\section{DAFTAR PUSTAKA}

Arikunto, Suharsimi, 2002. Prosedur Penelitian Suatu Pendekatan Praktik, Jakarta: Rineka Cipta.

Sugiono, 2000. Statistika untuk penelitian. Bandung : CV. Alvabeta.

Dwiyogo, D, Wasis dan Karwono.1992. Metode Eksperimen dalam Penelitian Pendidikan. Malang: IPTPI Cabang Malang Program Pasca Sarjana Malang.

Aslan, L.M, 2008. Budidaya Tanaman obat. Penerbit Karnisius. Yogyakarta

Dahuri, Rokhmin., Rais, Jacub., Ginting, Sapta P., dan Sitepu J. 2000. Pengelolaan Sumber Daya Wilayah Pesisir dan Lautan Secara Terpadu. PT Pradnya Paramitha. Jakarta. 
Dimyati, Ratih D. dan Dimyati, Muhammad. 1990. Remote Sensing dan Sistem Informasi Geografis untuk Perencanaan. Fakultas Teknik Universitas Muhammadiyah Jakarta. Jakarta.

Direktorat Jenderal Perikanan Budidaya. 2005. Profil Tanaman obat Indonesia. Direktorat Pembudidayaan Departemen Kelautan dan Perikanan, Jakarta

Djurdjani, 1999. Konsep pemetaan. On The Job Training (OTJ) Mengenai Aplikasi SIG untuk Perencanaan dan Pengelolaan Wilayah Pesisir Secara Terintegrasi di Sepuluh Propinsi Wilayah MCMA. PUSPICS Fakultas Geografi Universitas Gajah Mada. Yogyakarta

Basuki, I. dan D. Sheil. 2004. Prioritas masyarakat lokal dalam pengelolaan sumber daya lahan hutan di hulu sungai Malinau, Kalimantan Timur. Environmental Services Briefs, CIFOR, Bogor, 4p.

Frazier, S. 1990. Distribution dan Status of Crocodile Populations in Irian Jaya Indonesia. Dalam: Crocodiles. Proc. of the 9th Working Meeting of the IUCN/SSC Crocodile Specialist Group, Lae, Papua New Guinea. Vol.1. pp 208-250. IUCN-The World Conservation Union Publ. N.S. Gldan, Switzerldan.

Phillips, A. 2004. The Durban Action Plan, revised version, march 2004, IUCN, Vth World Parks Congress, 38p.

Richards, S. J. dan S. Suryadi (eds). 2002. A Biodiversity Assessment of Yongsu - Cyclops Mountains dan the Southern Mamberamo Basin, Papua, Indonesia. RAP Bulletin of Biological Assessment. Conservation International, Washington, DC, USA.

Sheil, D., R.K. Puri, I. Basuki, M. Van Heist, M. Wan, N. Liswanti, Rukmiyati, M.A. Sardjono, I. Samsoedin, K. Sidiyasa, Chrisdanini, E. Permana, E.M. Angi, F. Gatzweiler, B. Johnson dan A. Wijaya. 2004.

Mengeksplorasi keanekaragaman hayati, lingkungan dan pandangan masyarakat lokal mengenai berbagai lanskap hutan; metode-metode penilaian lanskap secara multidisipliner, CIFOR, Bogor, $101 \mathrm{p}$.

Sheil, D., N. Liswanti, I. Basuki, M. Wan, I. Samsoedin, K. Kartawinata, Rukmiyati dan M. Agung. 2003. Prioritas lokal dan keanekaragaman hayati dalam lansekap hutan: apa penting menurut masyarakat? Dalam: Jurnal Hutan Indonesia.

Sheil, D. dan A. Lawrence. 2004. Tropical biologists, local people dan conservation: new opportunities for collaboration. Dalam: TRENDS in Ecology dan Evolution, vol.19 (12): 634-638. 